\title{
Recent Advances in the Acclimation Mechanisms and Genetic Improvement of Peanut for Drought Tolerance
}

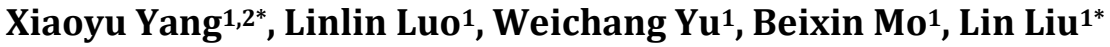 \\ ${ }^{1}$ Guangdong Provincial Key Laboratory for Plant Epigenetics, Longhua Bioindustry and Innovation Research Institute, \\ College of Life Sciences and Oceanography, Shenzhen University, Shenzhen, China \\ ${ }^{2}$ Key Laboratory of Optoelectronic Devices and Systems of Ministry of Education and Guangdong Province, \\ College of Optoelectronic Engineering, Shenzhen University, Shenzhen, China \\ Email: *xyyang-1982@163.com, *linliu@szu.edu.cn
}

How to cite this paper: Yang, X.Y., Luo, L.L., Yu, W.C., Mo, B.X. and Liu, L. (2019) Recent Advances in the Acclimation Mechanisms and Genetic Improvement of Peanut for Drought Tolerance. Agricultural Sciences, 10, 1178-1193.

https://doi.org/10.4236/as.2019.109088

Received: August 27, 2019

Accepted: September 23, 2019

Published: September 26, 2019

Copyright $\odot 2019$ by author(s) and Scientific Research Publishing Inc. This work is licensed under the Creative Commons Attribution International License (CC BY 4.0).

http://creativecommons.org/licenses/by/4.0/

\begin{abstract}
Peanut (Arachis hypogaea L.) is one of the most important oilseed crops that are cultivated worldwide. Peanut production is now greatly limited by drought stress, which is a major environmental challenge. The urgent task for current peanut research is thus to study the underlying mechanisms of peanut drought tolerance, to identify genes that are closely associated with drought tolerance, and to create new germplasms/varieties with high drought tolerance. In this review, we summarize recent advances in the acclimation mechanisms to water deficiency and the genetic improvement of peanut for drought tolerance, and propose the perspectives for the future peanut research.
\end{abstract}

\section{Keywords}

Arachis hypogaea, Acclimation, Drought Tolerance, Genetic Improvement

\section{Introduction}

Cultivated peanut (Arachis hypogaea L.) is an allotetraploid crop $(2 \mathrm{n}=4 \mathrm{x}=40$, $\mathrm{AABB}$ ) and belongs to Arachis section of Leguminosae family. It originates in South America and perhaps evolves from the hybridization of two putative progenitors, Arachis duranensis and Arachis ipaënsis, followed by genome duplication and domestication events. Recently, comparative karyotyping analysis via FISH (florescence in situ hybridization) reveals that chromosome organization is highly conserved in cultivated peanut and its two putative progenitors, especially in the B genome chromosomes. However, variations exist between Arachis du- 
ranensis and the A genome chromosomes in cultivated peanut, especially for the distribution of ITRs (interstitial telomere repeats). Further analyses of additional Arachis duranensis varieties from different geographic regions reveal both numeric and positional variations of ITRs in their chromosomes, which are similar to the variations in tetraploid peanut varieties. These results provide evidence for the origin of cultivated peanut from the two diploid ancestors, and suggest that multiple hybridization events of Arachis ipaënsis with different varieties of Arachis duranensis may have occurred during the evolution of cultivated peanut (Figure 1) [1] [2]. The multiple hybridization hypothesis has also been partially supported by the results of genome sequencing for cultivated peanut and the two putative progenitors [3] [4] [5] [6].

Peanut is one of the most important oilseed crops and widely cultivated in the world. China is one of the main countries for peanut production and consumption, wherein the field for peanut cultivation and the annual yield are the greatest (4.608 million hectares and 17.092 million tons) among oilseed crops [7]. Peanut seeds are enriched in many kinds of nutrition such as unsaturated fatty acids, proteins, sugars, vitamins and mineral elements, and are usually used as fresh and processed foods as well as oil production, which are welcomed by

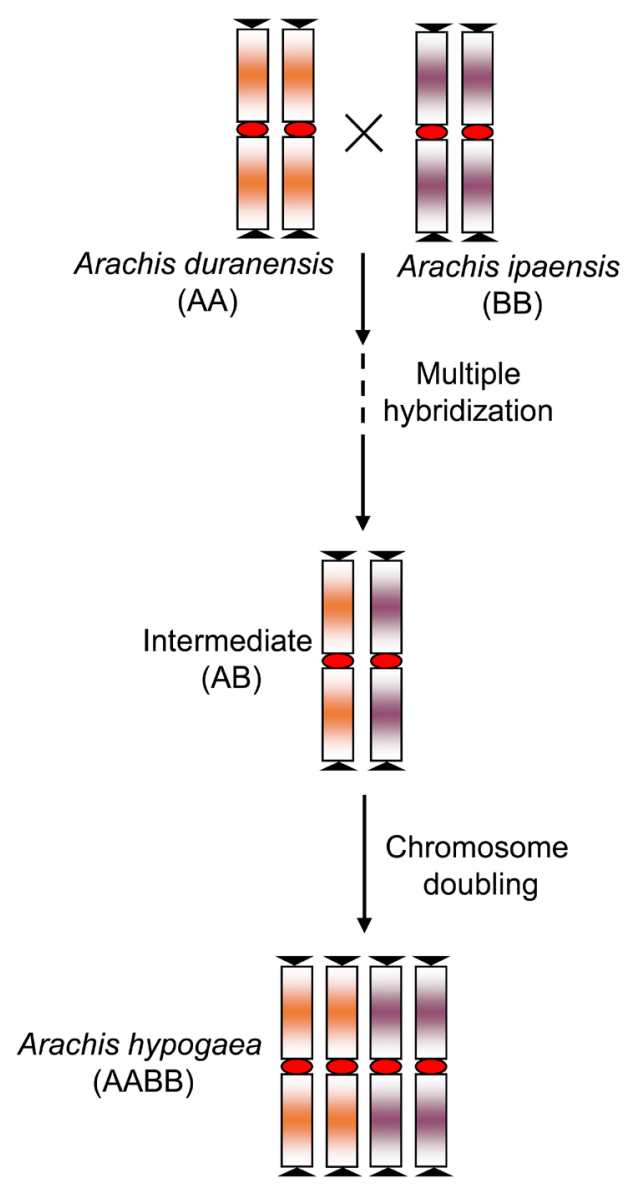

Figure 1. Schematic illustration for cultivated peanut origin and evolution [1]. 
billions of consumers. Nowadays, the supply and consumption of plant oil are largely unbalanced and over $60 \%$ of edible oil consumption depends on export to China, seriously threatening the national safety of edible oil [8]. In comparison to oilseed crops such as soybean and rapeseed, peanut displays many obvious advantages including higher yield per unit field, higher efficiency of oil production per unit weight and labor-saving field management, and therefore, plays a critical role in agricultural production in China [9].

However, global climate change is dramatically aggravated and has resulted in frequent occurrences of drought with gradually increased seriousness, which imposes negative influences on peanut production such as yield loss, lowered seed quality, and increased damages from diseases and pests. It has been reported that over $30 \%$ of peanut yield loss is attributed to water deficiency in approximately $70 \%$ of peanut cultivation area in China [10]. Drought stress is thus considered as the most serious environmental stress in peanut production in China [11]. To unveil the underlying mechanisms about peanut acclimation to drought stress has become an urgent need for current peanut research in China. Peanut genes related to drought tolerance are needed for the creation of new peanut germplasms with high drought tolerance as well. In this review, we summarize recent advances in peanut research about the acclimation mechanisms underlying drought tolerance and its genetic improvement, and propose some perspectives for future peanut research.

\section{Effects of Drought Stress on Cultivated Peanut}

\subsection{Effects of Drought Stress on Growth, Development and Yield of Peanut}

Under drought stress, peanut organs can be influenced to different extents. For example, peanuts grown under moderate drought stress display the increased root to shoot ratio and the enhanced root length and density, particularly in the deep soil, in comparison to those grown under normal growth condition [12] [13]. Peanut root activity can be stimulated by water deficiency, and thus water absorption and root growth can be returned to the normal level rapidly after re-watering [12] [13]. Peanuts under long-term drought stress can greatly decrease root length, root density, total area of absorption and activity [14] [15]. Consequently, the water usage efficiency, internode length, node and tiller numbers of peanut plants can be significantly lowered [14] [15]. Sankar et al. [16] also reported that in comparison to plants under normal growth condition, peanuts stressed by water deficiency displayed some seriously damaged phenotypes including the smaller and curled leaves, the decreased thickness of leaf epidermis and hypodermis, the altered structure and number of mesophylls, the dwarfed aerial parts and the deceased accumulation of assimilates. In addition, peanut yield can be largely reduced by drought stress because of the delayed flower bud differentiation and anthesis, the reduced flower and pod numbers, and the extended growth period [15] [17]. 
Because of the variations in water demand, peanut usually displays variable tolerance to drought stress at different developmental stages. Water demand is the least at germination stage and the occurrence of drought stress at this stage can inhibit the germination of peanut seeds [18]. Consequently, the germination rate is significantly decreased [18]. The growth of aerial parts of peanut seedlings is largely limited under drought stress, while great complementary effects can be observed in drought stressed seedlings after re-watering [19]. Therefore, water control at seedling stage can benefit peanut growth and yield [19]. Peanut at flowering and podding stages becomes very sensitive to water deficiency, and the limitation of water supply can largely decrease flower and pod numbers, thus reducing peanut yield [20]. The occurrence of water limitation at seed-filling stage has negative effects on peanut quality and yield such as the decreasing of pod fullness, the lowering of kernel to pod ratio, and the declining of oil content [21].

\subsection{Effects of Drought Stress on Physiological and Biochemical Processes in Peanut}

Water deficiency can alter physiological and biochemical processes in cultivated peanut. Zhang et al. [22] reported that peanut plants withered under drought stress because of water leakage and the decreased tensions of cells and tissues. The disorders of plant hormones and soluble metabolites together with the inhibition of protein and fat biosynthesis were also observed in stressed plants [22]. Photosynthesis is a basic physiological process and plays a critical role in plant growth, development and production. Under drought stress, chlorophyll content in peanut leaves is changed in a variety-dependent manner. The increased content of chlorophyll is observed in the leaves of peanuts with high drought tolerance, while that in the leaves of drought sensitive peanuts is dramatically decreased [23]. However, the lowered ratio of chlorophyll a to chlorophyll b can be found in the leaves of both drought tolerant and sensitive varieties [23]. Qin et al. [24] reported that light and dark reactions such as primary light-energy conversion, electron transfer and photophosphorylation were greatly inhibited in drought stressed peanuts, resulting in the disturbance of photosynthesis. Water deficiency leads to the dissociation of oxidative phosphorylation and photophosphorylation, and further inhibits the biosynthesis of ATP (adenosine triphosphate) [25]. As a result, the metabolism of assimilates and energy is interrupted and respiration is also decreased in peanut plants [25]. In addition, nitrogen fixation and mineral element absorption are negatively influenced in peanuts under water deficiency condition [26].

\section{The Underlying Mechanisms for Peanut Drought Tolerance}

Peanut can adopt three different strategies to cope with water deficiency: drought escape, drought avoidance and drought tolerance. A plethora of studies have provided morphological, physiological, biochemical, and molecular expla- 
nations for the mechanisms regarding peanut drought tolerance.

\subsection{Morphological Basis for Peanut Drought Tolerance}

Previous studies have demonstrated that in comparison to drought sensitive ones, peanuts with high tolerance have more complex root system including greater root fresh weight, total length and surface area, and can well adjust water usage efficiency when exposing to water deficiency condition by optimizing the spatial distribution of root such as the increasing of root length, surface area and volume in soil, especially in the deep soil [5]. Under heavy drought stress, the inhibitory effects on the growth of root and aerial parts are lighter for drought tolerant peanuts than sensitive ones [27]. Different leaf morphologies have also been observed among peanut plants with different drought tolerance and the higher leaf thickness, the greater ratio of palisade cells to spongy mesophyll, the greater specific leaf weight and leaf area per plant are detected in drought tolerant peanuts than in the sensitive ones under both normal growth condition and water deficiency condition [28].

\subsection{Physiological Basis for Peanut Drought Tolerance}

Osmotic regulation is one of the most significant mechanisms underlying the acclimation of plants to drought stress. There are two main categories of osmotically active substances: one is the absorbed inorganic ions by root such as $\mathrm{Na}^{+}$ and $\mathrm{K}^{+}$, and the other is small organic molecules that are synthesized endogenously in plants such as soluble sugars, soluble proteins, and proline [29]. The dramatically increased content of soluble proteins and free amino acids can be observed in peanut leaves very shortly after the exposure of plants to drought stress, while the content of these osmotically active substances is gradually decreased with the extension of water deficiency period [30]. The increased content of osmotic substances can be detected in drought stressed peanuts overall developmental stages, especially during flowering period [30]. The capacity of osmotic regulation is different among these osmotic substances, and the best is soluble proteins followed by soluble sugars, free amino acids and finally proline.

Oxidation-reduction enzyme system plays crucial roles in the acclimation of peanut to water deficiency as well. In a study regarding the effects of drought stress on redox system in peanut root nodes, Furlan et al. [31] reported that the activities of POD (peroxidase), APX (ascorbateperoxidase) and GR (glutathione reductase) were increased significantly, while no significant changes were observed in the activity of SOD (superoxide dismutase). Xiong et al. [20] investigated the responses of redox system to water deficiency in peanuts with different tolerance and found that the activity of CAT (catalase) was significantly enhanced in the leaves of high tolerant varieties, while in drought sensitive varieties the activity of CAT was increased slightly or decreased and the content of MDA (malondialdehyde) was increased greatly, leading to growth inhibition and yield loss. In comparison to other developmental stages, physiological processes, 
agricultural traits and yield of peanut were influenced mostly during podding period, indicating a development-dependent response of redox system to drought stress in peanut [20].

In addition, the involvement of plant hormones such as ABA (abscisic acid) has been revealed in the acclimation of peanut to water deficiency [32]. For example, the content of $\mathrm{ABA}$ is significantly increased in plant root when water supply is limited, and the accumulated $\mathrm{ABA}$ is further transported to aerial parts of stressed plants via xylems for the adjustment of osmotic potential and the regulation of stomatal movement, thus protecting plants from excessive water loss under drought stress [33] [34]. Moreover, the drought-induced variations of ABA content display a variety-dependent manner and greater ABA accumulation is observed in plants with high drought tolerance [32].

\subsection{Molecular Basis for Peanut Drought Tolerance}

Recently the rapid development of molecular biology and related technologies has deepened our understanding on the mechanisms of drought tolerance in peanut, and genes that encode drought tolerance-related proteins and peptides have been successfully cloned in peanut. For example, Dramé et al. [35] investigated the expression profiles of PLDa (phospholipase Da), cysteine protease, tryptophan protease and LEA (late embryogenesis abundant) proteins in the leaves of peanut seedlings that were grown under water-limited condition and re-watering condition, respectively, and found that the expression of PLD $\alpha$ and $L E A$ was dramatically enhanced, while the expression of cysteine protease and tryptophan protease was decreased significantly in high tolerant peanuts than that in drought sensitive ones. After re-watering, the expression of the above mentioned four genes was returned to the normal level faster in the drought tolerant peanuts than in the sensitive ones [35]. The authors thus proposed that the distinct expression profiles of these four genes might be important reasons for the variable drought tolerance of peanuts underwater-limited condition [35]. Proteomic analysis has been performed on peanuts with different drought tolerance by Kottapalli et al. [36], and the results reveal that genes such as $A C C$ (acetyl CoA carboxylase), LOX (lipoxygenase) and IPS (inositol phosphate synthase) might be involved in the acclimation of germinated peanut seeds to water deficiency [36]. Furthermore, a number of drought-responsive transcriptional factors such as $b Z I P$ (basic leucine zipper), $M Y B$ ( $v$-myb avian myeloblastosis viral oncogene homolog) and AP2-EREB (APETALA2/ ethylene responsive element binding) have been uncoveredvia high throughput sequencing in peanut [37] [38]. By analyzing ESTs (expressed sequence tags), Pruthvi et al. [39] observed that the expression of CTL (cyclin T-like), ARL (aldehyde reductase-like), CKL (cholin kinase-like) and PAPL (proline amino peptidase-like) was greatly stimulated in drought stressed peanut plants. Functional analysis of peanut ATL1 ( $A B A$ transporter-like 1) has been performed by Ge et al. [40], who showed that overexpression of peanut ATL1 in Arabidopsis decreased the sensitivity to 
the exogenous application of $\mathrm{ABA}$ and drought tolerance in comparison to Mock plants, revealing the negative involvement of $A T L 1$ gene in peanut drought tolerance. In addition, miRNAs and epigenetically modified histone proteins have been reported to be involved in the adaption of peanut to water deficiency [41] [42] [43] [44] [45]. More efforts have been paid on the identification of drought-responsive genes in previous research regarding peanut drought tolerance, while functional analysis of these genes should be strengthened in the future.

\section{Genetic Improvement of Peanut for Drought Tolerance}

\subsection{Genetic Breeding}

Genetic hybridization has been the most widely used breeding strategy for the improvement of peanut drought tolerance. Peanut drought tolerance varies greatly among different germplasms. More tolerant varieties are found in the dragon type peanut such as "A596" and "Rugaoxiyangsheng" (Table 1), followed by Virginia type, Spanish type, intermediate type and Valencia type peanuts. Dragon type, Virginia type and Spanish type peanuts are widely used as parental lines for breeding drought tolerant varieties.

In comparison to cultivated ones, wild peanut varieties have higher genetic polymorphisms and contain more beneficial genetic resources that are responsible for drought tolerance, disease resistance and high productivity. Therefore, these wild peanut varieties are considered as invaluable germplasm resources for the improvement of cultivated ones. For example, by using wide crossing between wild and cultivated peanuts, scientists have successfully generated high oleic acid varieties, low palmitic acid varieties, early maturation varieties and

Table 1. Recently identified peanut germplasms with high drought tolerance.

\begin{tabular}{|c|c|}
\hline Peanut germplasms with high drought tolerance & References \\
\hline $\begin{array}{l}\text { “Tangke 8", "Jihua 2", "Jihua 4", "Huayu 25”, "Huayu 17”, "Huayu 22", } \\
\text { "Datangyou" and "Huayu 21" }\end{array}$ & [14] \\
\hline $\begin{array}{l}\text { "Huayu 17", "Huayu 25", “Tangke 8", "Fenghua 1", "Luhua 14", "Jihua 4" } \\
\text { and "Huayu } 27 \text { " }\end{array}$ & [46] \\
\hline "Shanhua 11", "Rugaoxiyangsheng" and "A596" & [47] \\
\hline "A596", "Shanhua 11" and "Rugaoxiyangsheng" & [28] \\
\hline "L19", "L121" and "L146" & [48] \\
\hline "Yuanza 9307" & [49] \\
\hline “\#11”, “\#34” and “\#49” & [50] \\
\hline "Zhonghua 8" and "Xianghua 55" & [51] \\
\hline “Taihua 4", "Xuhua 13", “Tai 0125" and "Tai 0005” & {$[52]$} \\
\hline "Yueyou 7" & [45] \\
\hline "Yuanza 9102", "Ji 0212-4", "Xianghua 2008" and "NC6" & [53] \\
\hline
\end{tabular}


disease resistance varieties [54] [55] [56] [57] [58]. However, there are still bottlenecks limiting the application of wide crossing in current peanut breeding such as hybridization incompatibility, low survival rate of hybrids, sterility of hybrids and the segregation of elite traits [59].

\subsection{Mutation Breeding}

Mutation breeding is an important method for crop improvement. Mutations are commonly produced by radiation and chemical reagents. Compared to conventional genetic hybridization, mutation breeding can rapidly create large numbers of novel genetic alleles that do not exist in nature. For example, by using radiation breeding, new peanut germplasms with drought tolerance, saline-alkaline tolerance, disease resistance and so on, have been created [59]. In addition, peanut mutants with high yield, big or small seeds have been generated via chemical mutagenesis [60] [61] [62] [63].

\subsection{Cyto-Engineering Breeding}

Cyto-engineering breeding is a strategy for creation of new plant germplasms or new varieties with improved agronomic traits through modifying plant cells according to the expected targets of breeding. This technology is developed on basis of totipotency of plant cells and can be classified as anther culture, embryo culture, protoplast culture, somatic hybridization, chromosome transferring and so on. The greatest advantage of cyto-engineering is the overcoming of hybridization barriers as comparing with other breeding strategies, and thus lots of genetically improved crops including wheat, tomato, potato and orange have been created [59]. However, the application of cyto-engineering breeding in current peanut improvement still lags behind other crops largely due to the lack of basic knowledge about peanut cyto-engineering and physiological mechanisms, the low efficiency of hybrid regeneration, and so on [64] [65].

\subsection{Molecular Breeding}

Cultivated peanut is one of the only two tetraploidy species in the Arachis family and is reproductively isolated from wild peanut varieties, of which most are diploid. Therefore, wild germplasm resources that can be used for genetic improvement of cultivated peanut varieties have been greatly limited. In the past several years the technologies for peanut somatic embryogenesis and agrobacterium-mediated transformation have been well developed, thus promoting the improvement of cultivated peanut via genetic engineering. There are two systems for peanut transformation: bombardment-mediated transformation of calli and agrobacterium-mediated transformation of explants such as embryo leaflets, cotyledons and hypocotyls, and both can generate transgenic plantlets through somatic embryogenesis [66] [67].

Drought tolerance can be improved via genetic engineering. Bhatnagar-Mathur et al. [68] transformed "JL24", a drought sensitive peanut variety, with Arabi- 
dopsis DREB $1 A$ (dehydration-responsive element-binding protein $1 A$ ) gene that was driven by a stress-inducible promoter, and the improved transpiration efficiency was observed in transformed peanut plants. Vadez et al. [69] and Devi et al. [70] reported significantly increased drought tolerance of peanut "JL24" when it was transformed with a peanut-derived DREB1Agene, of which the overexpression improved water usage efficiency of transgenic "JL24" via the stimulation of root system and the decreasing of transpiration rate. Tan et al. [71] overexpressed a NCED1 (9-cis-epoxycarotenoid dioxygenase1) gene under the $35 \mathrm{~S}$ promoter in cultivated peanuts and observed that $\mathrm{ABA}$ content was significantly increased in the aerial parts of transgenic plants. After exposing to 10-h PEG6000-medaited drought stress, the expression of $N C E D 1$ gene was dramatically stimulated and the content of endogenous ABA was enhanced, while the level of reactive oxygen species was lowered in the leaves of $N C E D 1$-overexpressed peanuts [71]. Additionally cultivated peanuts that overexpress Arabidopsis-derived IPT (adenylate isopentenyltransferase), or NHX1 (sodium/hydrogen exchanger1), or AVP1 (pyrophosphate-energized vacuolar membrane proton pump 1), or Aeluropus sinensis-derived $D R E B 1 A$ display significantly increased drought tolerance in comparison to wild type plants under water deficiency condition, and the improvement of growth performance, photosynthesis and transpiration is observed in the transgenic peanut plants, thus obtaining higher yield [53] [72] [73] [74].

\section{Perspectives}

Peanut is one of drought tolerant crops, and has great potentials in the utilization of arid/semi-arid field and the development of dryland agriculture in China. However, high drought tolerant peanut varieties such as dragon type (Table 1) often display bad agronomic performance while those with good agronomic performance are often sensitive to water deficiency. There is an urgent need to study the molecular mechanisms underlying peanut drought tolerance and to identify genes responsible for drought tolerance, which will benefit the breeding of new peanut varieties with both good agronomic performance and high drought tolerance in the future.

In the past several years, targeted genome engineering technologies such as CRISPR/Cas9 (clustered regularly interspaced short palindromic repeats/CRIPSR-associated protein 9) have been successfully used for mutation of target genes in crops [75] [76], demonstrating the great potentials in crop improvement. The CRISPR/Cas9 system is commonly composed of a Cas9 endonuclease and a sgRNA. The sgRNA that harbors a 20- or 19-bp sequence base-pairing with target site in plant genome can form a complex with Cas9 and then guides this complex to bind the target site. Thereafter the Cas9-mediated breakage occurs at the target site. The mutations/modifications will be introduced into the plant genome when the breakage site is repaired. With the aid of CRIPSR/Cas9 technology, we could obtain new peanut germplasms with high drought tolerance. For example, the identified negative regulators such as peanut 
ATL1 (ABA transporter-like 1) [40] could become candidate targets for genetical modifications via CRISPR/Cas9 system, enabling peanut plants to be resistant to drought stress. Although complete knockouts of these negative regulators might compromise the normal growth and production of peanut under non-stress condition, the engineered peanuts could be used in the arid/semi-arid area, where water deficiency is constantly threatening the peanut production. Most importantly, these engineered materials will be transgene-free because the construct of CRISPR/Cas9 can be segregated in the siblings by genetic hybridization, thus being able to be accepted by the public.

\section{Acknowledgements}

This work was supported by Natural Science Foundation of Guangdong Province (2018A030310446), China Postdoctoral Science Foundation (2017M612741), National Natural Science Foundation of China (31671766) and Guangdong Innovation Research Team Fund (2014ZT05S078).

\section{Conflicts of Interest}

The authors declare no conflicts of interest regarding the publication of this paper.

\section{References}

[1] Zhang, L., Yang, X., Tian, L., Chen, L. and Yu, W. (2016) Identification of Peanut (Arachis hypogaea L.) Chromosomes by a Fluorescence in Situ Hybridization System Reveals Multiple Hybridization Events during Tetraploid Peanut Formation. New Phytologist, 211, 1424-1143. https://doi.org/10.1111/nph.13999

[2] Wang, X., Xiao, L., Dong, A., Wang, T., Qian, Q., Qi, X., Chen, F., Zuo, J., Yang, S., Gu, H., Chen, Z., Jiang, L., Bai, Y., Kong, H. and Chong, K. (2017) Important Advance in Several Research Fields of Plant Sciences in China for 2016. Chinese Bulletin of Botany, 52, 394-452.

[3] Chen, X., Li, H., Pandey, M.K., Yang, Q., Wang, X., Garg, V., Li, H., Chi, X., Doddamani, D., Hong, Y., Upadhyaya, H., Guo, H., Khan, A.W., Zhu, F., Zhang, X., Pan, L., Pierce, G.J., Zhou, G., Krishnamohan, K.A., Chen, M., Zhong, N., Agarwal, G., Li, S., Chitikineni, A., Zhang, G.Q., Sharma, S., Chen, N., Liu, H., Janila, P., Li, S., Wang, M., Wang, T., Sun, J., Li, X., Li, C., Wang, M., Yu, L., Wen, S., Singh, S., Yang, Z., Zhao, J., Zhang, C., Yu, Y., Bi, J., Zhang, X., Liu, Z.J., Paterson, A.H., Wang, S., Liang, X., Varshney, R.K. and Yu, S. (2016) Draft Genome of the Peanut A-Genome Progenitor (Arachis duranensis) Provides Insights into Geocarpy, Oil Biosynthesis, and Allergens. Proceedings of the National Academy of Sciences of the United States of America, 113, 6785-6790.

https://doi.org/10.1073/pnas.1600899113

[4] Bertioli, D.J., Jenkins, J., Clevenger, J., Dudchenko, O., Gao, D., Seijo, G., Leal-Bertioli, S.C.M., Ren, L., Farmer, A.D., Pandey, M.K., Samoluk, S.S., Abernathy, B., Agarwal, G., Ballén-Taborda, C., Cameron, C., Campbell, J., Chavarro, C., Chitikineni, A., Chu, Y., Dash, S., El Baidouri, M., Guo, B., Huang, W., Kim, K.D., Korani, W., Lanciano, S., Lui, C.G., Mirouze, M., Moretzsohn, M.C., Pham, M., Shin, J.H., Shirasawa, K., Sinharoy, S., Sreedasyam, A., Weeks, N.T., Zhang, X., 
Zheng, Z., Sun, Z., Froenicke, L., Aiden, E.L., Michelmore, R., Varshney, R.K., Holbrook, C.C., Cannon, E.K.S., Scheffler, B.E., Grimwood, J., Ozias-Akins, P., Cannon, S.B., Jackson, S.A. and Schmutz, J. (2019) The Genome Sequence of Segmental Allotetraploid Peanut Arachis hypogaea. Nature Genetics, 51, 877-884. https://doi.org/10.1038/s41588-019-0405-Z

[5] Chen, X., Lu, Q., Liu, H., Zhang, J., Hong, Y., Lan, H., Li, H., Wang, J., Liu, H., Li, S., Pandey, M.K., Zhang, Z., Zhou, G., Yu, J., Zhang, G., Yuan, J., Li, X., Wen, S., Meng, F., Yu, S., Wang, X., Siddique, K.H.M., Liu, Z.J., Paterson, A.H., Varshney, R.K. and Liang, X. (2019) Sequencing of Cultivated Peanut, Arachis hypogaea, Yields Insights into Genome Evolution and Oil Improvement. Molecular Plant, 12, 920-934. https://doi.org/10.1016/j.molp.2019.03.005

[6] Zhuang, W., Chen, H., Yang, M., Wang, J., Pandey, M.K., Zhang, C., Chang, W.C., Zhang, L., Zhang, X., Tang, R., Garg, V., Wang, X., Tang, H., Chow, C.N., Wang, J., Deng, Y., Wang, D., Khan, A.W., Yang, Q., Cai, T., Bajaj, P., Wu, K., Guo, B., Zhang, X., Li, J., Liang, F., Hu, J., Liao, B., Liu, S., Chitikineni, A., Yan, H., Zheng, Y., Shan, S., Liu, Q., Xie, D., Wang, Z., Khan, S.A., Ali, N., Zhao, C., Li, X., Luo, Z., Zhang, S., Zhuang, R., Peng, Z., Wang, S., Mamadou, G., Zhuang, Y., Zhao, Z., Yu, W., Xiong, F., Quan, W., Yuan, M., Li, Y., Zou, H., Xia, H., Zha, L., Fan, J., Yu, J., Xie, W., Yuan, J., Chen, K., Zhao, S., Chu, W., Chen, Y., Sun, P., Meng, F., Zhuo, T., Zhao, Y., Li, C., He, G., Zhao, Y., Wang, C., Kavikishor, P.B., Pan, R.L., Paterson, A.H., Wang, X., Ming, R. and Varshney, R.K. (2019) The Genome of Cultivated Peanut Provides Insight into Legume Karyotypes, Polyploid Evolution and Crop Domestication. Nature Genetics, 51, 865-876.

https://doi.org/10.1038/s41588-019-0402-2

[7] Gao, Z., Jiang, J., Tang, X., Liu, J., Zhong, R., Han, Z., Xiong, F., Huang, Z., Wu, H., Li, Z., He, L. and Tang, R. (2018) Peanut Varieties Selection and Soil Properties Changes under Paddy-Upland Rotation. Journal of Southern Agriculture, 49, 2403-2409.

[8] Zhang, Z., Dai, L., Li, M., Yu, Q., Zhang, Y. and Wan, S. (2013) Present Status and Development Countermeasures of Peanut Seed Industry. Journal of Agricultural Science and Technology, 15, 30-37.

[9] Wan, S. (2014) Situation and Developing Strategy of Peanut Industry. Shandong Agricultural Sciences, 46, 128-132.

[10] Wan, L., Su, W., Li, B., Lei, Y., Yan, L., Kang, L., Huai, D., Chen, Y., Jiang, H. and Liao, S. (2018) Molecular Analysis of Formation of Drought Tolerance Traits in Peanut. Chinese Journal of Oil Crop Sciences, 40, 335-343.

[11] Ding, H., Zhang, Z., Dai, L., Song, W., Kang, T. and Ci, D. (2013) Responses of Root Morphology of Peanut Varieties Differing in Drought Tolerance to Water-Deficient Stress. Acta Ecologica Sinica, 33, 5169-5176. https://doi.org/10.5846/stxb201206120843

[12] Rowlanda, D.L., Faircloth, W.H., Payton, P., Tissue, D.T., Ferrell, J.A., Ronald, B., Sorensen, R.B. and Butts, C.L. (2012) Primed Acclimation of Cultivated Peanut (Arachis hypogaea L.) through the Use of Deficit Irrigation Timed to Crop Developmental Periods. Agricultural Water Management, 113, 85-95. https://doi.org/10.1016/j.agwat.2012.06.023

[13] Yao, Z., Xia, G., Wang, S., Hu, J. and Chi, D. (2016) Research Progress of the Effects of Water Stress on Peanut. Chinese Journal of Oil Crop Sciences, 38, 699-704.

[14] Zhang, Z., Dai, L., Ding, H., Chen, D., Yang, W., Song, W. and Wan, S. (2012) Identification and Evaluation of Drought Resistance in Different Peanut Varieties 
Widely Grown in Northern China. Acta AgronomicaSinica, 38, 495-504. https://doi.org/10.3724/SP.J.1006.2012.00495

[15] Zhang, G., Shi, X., Ci, D., Ding, H., Yang, J., Tian, J., Zhang, Z. and Dai, L. (2019) Effects of Drought and Salt Stress on Accumulation of Plant Dry Weight and Photosynthetic Characteristics. Journal of Nuclear Agricultural Sciences, 33, 999-1005.

[16] Sankar, B., Karthishwaran, K. and Somasundaram, R. (2013) Leaf Anatomical Changes in Peanut Plants in Relation to Drought Stress with or without Paclobutrazol and Abscisic Acid. Journal of Phycology, 5, 25-29.

https://www.semanticscholar.org/paper/Leaf-anatomical-changes-in-peanut-plantsin-to-with-Sankar-Karthishwaran/ff26da280e7b95d14b93f002380d48658121a058

[17] Kang, T., Dai, L., Li, W., Li, D., Zhang, Y., Ding, H., Chen, J., Zhang, L., Ren, Z. and Zhang, Z. (2017) Effect of Drought Stress on Root Physiological Characteristics, Yield and Quality of Different Peanut Varieties. Journal of Peanut Sciences, 46, 53-58.

[18] Cheng, X., Zhao, C., Wang, M., Wang, Y. and Shan, G. (2010) Effects of Drought Stress at Different Growth Stages on Drought Resistance Index and Yield of Peanut. Journal of Qingdao Agricultural University (Natural Sciences), 27, 282-284.

[19] Liu, J., Zhao, C., Wu, N., Wang, Y. and Wang, M. (2011) Effects of Drought and Rewatering at Seedling Stage on Photosynthetic Characteristics and Water Use Efficiency of Peanut. Scientia Agricultura Sinica, 44, 469-476.

[20] Xiong, J., Li, S., Chen, L., Zou, X., Song, L. and Zou, X. (2016) Effects of Drought Stress on Physiological Traits and Yield of Different Drought-Tolerant Peanut Varieties. Acta Agriculturae Jiangxi, 28, 1-5.

[21] Sun, H., Yu, H., Yu, S., Ren, L., Shi, P., Sun, Y. and Zhao, C. (2015) Recent Advance in Physiological Mechanisms of Peanut Drought Tolerance. Agricultural Science and Technology Communications, No. 4, 243-246.

[22] Zhang, T., Dai, C., Wang, M., Wang, Y., Zhang, X. and Zou, X. (2018) Effects of Coronation on Photosynthetic Characteristics and Endogenous Hormone Contents of Peanut Seedlings under Drought Stress. Journal of Qingdao Agricultural University (Natural Sciences), 35, 207-212.

[23] Sun, A., Wan, Y., Liu, F., Zhang, K. and Qin, X. (2010) Effects of Drought Stress on Photosynthetic Characteristics and Yield of Different Peanut Varieties. Shandong Agricultural Sciences, No. 10, 32-38.

[24] Qin, L., Zhang, Y. and Guo, F. (2011) Damaging Mechanisms of Peanut (Arachis hypogaea L.) Photosystems Caused by High-Temperature and Drought under High Irradiance. Acta Ecologica Sinica, 31, 1835-1843.

http://www.wanfangdata.com.cn/details/detail.do?_type=perio\&id=stxb201107009

[25] Liu, M., Lv, A., Wu, J., Li, X. and Wang, Q. (2014) A Review of Impacts of Drought on Agro-Ecosystem. Chinese Agricultural Science Bulletin, 30, 165-171.

[26] Zhang, G., Zhang, Z., Ci, D., Ding, H., Yang, J., Shi, X., Tian, J. and Dai, L. (2018) Effects of Drought and Salt Stress on Osmotic Regulator and Antioxidase Activities. Acta Agriculturae Boreali-Sinica, 33, 176-181.

[27] Potters, G., Pasternak, T.P., Guisez, Y., Palme, K.J. and Jansen, M.A. (2007) Stress-Induced Morphogenic Responses: Growing out of Trouble? Trends in Plant Science, 12, 98-105. https://doi.org/10.1016/j.tplants.2007.01.004

[28] Li, G., Zhang, K., Liu, F., Liu, D. and Wan, Y. (2014) Morphological and Physiological Traits of Leaf in Different Drought Resistant Peanut Cultivars. Scientia Agricultura Sinica, 47, 644-654. 
[29] Gao, Q., Jia, S., Miao, Y., Lu, X. and Li, H. (2016) Effects of Exogenous Melatonin on Nitrogen Metabolism and Osmotic Adjustment Substances of Melon Seedlings under Sub-Low Temperature. Chinese Journal of Applied Ecology, 27, 519-524.

[30] Zhang, Z., Dai, L., Song, W., Ding, H., Ci, D., Kang, T., Ning, T. and Wan, S. (2013) Effect of Drought Stresses at Different Growth Stages on Peanut Leaf Protective Enzyme Activities and Osmoregulation Substances Content. Acta Agronomica Sinica, 39, 133-141. https://doi.org/10.3724/SP.J.1006.2013.00133

[31] Furlan, A.L., Bianucci, E., Tordable, M.C., Castro, S. and Dietz, K.J. (2014) Antioxidant Enzyme Activities and Gene Expression Patterns in Peanut Nodules during a Drought and Rehydration Cycle. Functional Plant Biology, 41, 704-713. https://doi.org/10.1071/FP13311

[32] Zhu, J.K. (2016) Abiotic Stress Signaling and Responses in Plants. Cell, 167, 313-324. https://doi.org/10.1016/j.cell.2016.08.029

[33] Liu, F., Jensen, C.R., Shahanzari, A., Andersen, M.N. and Jacobsen, S.E. (2005) ABA Regulated Stomatal Control and Photosynthetic Water Use Efficiency of Potato (Solanum tuberosum L.) during Progressive Soil Drying. Plant Science, 168, 831-836. https://doi.org/10.1016/j.plantsci.2004.10.016

[34] Liu, C., Zhou, S., Zou, Y., Liang, D. and Ma, F. (2012) Changes of Endogenous Hormones Contents of Two Different Drought-Tolerant Malus Rootstocks in Response to Drought Stress. Agricultural Research in the Arid Areas, 35, 94-98.

[35] Dramé, K.N., Clavel, D., Repellin, A., Passaquet, C. and Zuily-Fodil, Y. (2007) Water Deficit Induces Variation in Expression of Stress-Responsive Genes in Two Peanut (Arachis hypogaea L.) Cultivars with Different Tolerance to Drought. Plant Physiology and Biochemistry, 45, 236-243. https://doi.org/10.1016/j.plaphy.2007.02.002

[36] Kottapalli, K.R., Rakwal, R., Shibato, J., Burow, G., Tissue, D., Burke, J., Puppala, N., Burow, M. and Payton, P. (2009) Physiology and Proteomics of the Water-Deficit Stress Response in Three Contrasting Peanut Genotypes. Plant Cell and Environment, 32, 380-407. https://doi.org/10.1111/j.1365-3040.2009.01933.x

[37] Guimarães, P.M., Brasilero, A.C.M., Morgante, C.V., Martins, A.C., Pappas, G., Silva, O.B.Jr., Togawa, R., Leal-Bertioli, S.C., Araujo, A.C., Moretzsohn, M.C. and Bertioli, D.J. (2012) Global Transcriptome Analysis of Two Wild Relatives of Peanut under Drought and Fungi Infection. BMC Genomics, 13, 387. https://doi.org/10.1186/1471-2164-13-387

[38] Zhao, X.B., Yan, C.X., Zhang, H., Wang, J., Li, C.J., Xie, H.F. and Shan, S.H. (2018) Differential Expression of Transcription Factor Families in Peanut (Arachis hypogaea) under Drought Stress. Journal of Agricultural Biotechnology, 26, 1143-1154. http://en.cnki.com.cn/Article_en/CJFDTotal-NYSB201807007.htm

[39] Pruthvi, V., Rama, N., Govind, G. and Nataraja, K.N. (2013) Expression Analysis of Drought Stress Specific Genes in Peanut (Arachis hypogaea L.). Physiology and Molecular Biology of Plants, 19, 277-281. https://doi.org/10.1007/s12298-012-0156-0

[40] Ge, K., Liu, X., Li, X., Hu, B. and Li, L. (2017) Isolation of an ABA Transporter-Like 1 Gene from Arachis hypogaea That Affects ABA Import and Reduces ABA Sensitivity in Arabidopsis. Frontiers in Plant Science, 8, 1150. https://doi.org/10.3389/fpls.2017.01150

[41] Mittal, M. (2014) Conserved and Novel microRNAs Identification and Expression Study in Response to Abiotic Stresses in Peanut (Arachis hypogaea). Texas Tech University, Lubbock. 
[42] Su, L.C., Deng, B., Liu, S., Li, L.M., Hu, B., Zhong, Y.T. and Li, L. (2015) Isolation and Characterization of an Osmotic Stress and ABA Induced histone deacetylase in Arachis hypogaea. Frontiers in Plant Science, 6, 512. https://doi.org/10.3389/fpls.2015.00512

[43] Gao, C., Wang, P., Zhao, S., Zhao, C., Xia, H., Hou, L., Ju, Z., Zhang, Y., Li, C. and Wang, X. (2017) Small RNA Profiling and Degradome Analysis Reveal Regulation of microRNA in Peanut Embryogenesis and Early Pod Development. BMC Genomics, 18, 220. https://doi.org/10.1186/s12864-017-3587-8

[44] Zhang, T., Hu, S., Yan, C., Li, C., Zhao, X., Wan, S. and Shan, S. (2017) Mining, Identification and Function Analysis of microRNAs and Target Genes in Peanut (Arachis hypogaea L.). Plant Physiology and Biochemistry, 111, 85-96.

https://doi.org/10.1016/j.plaphy.2016.11.018

[45] Chen, Y., Su, L. and Li, L. (2018) Effect of TSA on Photosynthesis-Related Gene Expression in Different Drought-Resistant Peanut Cultivars Subjected to Drought Stress. Journal of South China Normal University (Natural Sciences), 50, 72-77. http://www.wanfangdata.com.cn/details/detail.do?_type=perio\&id=hnsfdx20180301 $\underline{2}$

[46] Zhang, Z., Dai, L., Song, W., Ding, H., Chen, J. and Wan, S. (2012) Adaptability of Peanut Genotypes under Drought Stress. Chinese Journal of Oil Crop Sciences, 34, 377-383.

http://www.wanfangdata.com.cn/details/detail.do?_type=perio\&id=zgylzwxb201204 $\underline{007}$

[47] Liu, D., Wang, Y., Liu, F. and Zhang, K. (2013) Identification and Evaluation of Drought Resistance and Research of Leaf Drought Resistant Mechanisms in Peanut Varieties. Acta Agricultae Boreali-Sinica, 28, 206-213.

[48] Wang, J., Li, Y., Zhang, J., Cheng, Z., Chen, S., Song, Y., Kong, H., Wang, L. and Zhang, P. (2014) Identification Index of Drought Resistance in Peanut. Acta Agriculturae Boreali-Sinica, 29, 162-168.

[49] Zhang, J., Liu, J., Tang, F., Zang, X., Zhang, Z., Miao, L. and Xu, J. (2015) Differences in Physiological Traits of Drought Tolerance between Different Peanut Varieties. Jiangsu Agricultural Sciences, 43, 114-117.

[50] Shen, Y., Zhiguo, E., Zhang, X., Liu, Y. and Zhen, Z. (2015) Screening and Transcriptome Analysis of Water Deficiency Tolerant Germplasms in Peanut (Arachis hypogaea). Acta Physiologiae Plantarum, 37, 103. https://doi.org/10.1007/s11738-015-1840-9

[51] Liu, D., Wang, J., Li, L., Tan, H., Ma, J. and Lu, S. (2015) Responses of Different Peanut Cultivars to Drought and Waterlogging Stress and Physiological Mechanism. Acta Ecologica Sinica, 35, 3817-3823. https://doi.org/10.5846/stxb201309272375

[52] Liu, Y., Zhan, C., Shen, Y. and Chen, Z. (2016) Identification of Drought Tolerance in Peanut Varieties/Lines at the Germination Stage. Journal of Plant Genetic Resources, 17, 233-238.

[53] Wang, C., Wan, Y., Liu, F. and Zhang, K. (2018) Study on Drought Resistance of Peanut Varieties at Seedling Stage under PEG6000 Osmotic Stress. Shandong Agricultural Sciences, 50, 65-71.

[54] Raina, S.N., Rani, V., Kojima, T., Ogihara, Y., Singh, K.P. and Devarumath, R.M. (2001) RAPD and ISSR Fingerprints as Useful Genetic Markers for Analysis of Genetic Diversity, Varietal Identification, and Phylogenetic Relationships in Peanut (Arachis hypogaea) Cultivars and Wild Species. Genome, 44, 763-772. 
https://www.nrcresearchpress.com/doi/pdfplus/10.1139/g01-064

[55] Mallikarjuna, N. (2002) Gene Introgression from Arachis glabrata into A. hypogaea, A. duranensis and A. diogoi. Euphytica, 124, 99-105. https://doi.org/10.1023/A:1015630806935

[56] Wu, L., Chen, J., Hu, W. and Miao, H. (2003) A New Peanut Line 8126 Created through Hybridization with Wild Species A. cardenasii. Chinese Journal of Oil Crop Sciences, 25, 9-11.

[57] He, L., Tang, R. and Gao, G. (2005) Molecular Evidence for Gene Introgression from Wild Species to Cultivated Varieties in Peanut. Molecular Plant Breeding, 3, 815-820.

[58] Jiang, H., Ren, X., Huang, J., Lei, Y. and Liao, B. (2009) Genetic Variation of Fatty Acid Components in Arachis Species and Development of Interspecific Hybrids with High Oleic and Low Palmitic Acids. Acta Agronomica Sinica, 35, 25-32. https://doi.org/10.3724/SP.J.1006.2009.00025

[59] Chen, M., Chi, X., Pan, L., Chen, N., Yang, Z., Wang, T., Wang, M. and Yu, S. (2014) The Development Progress and Prospects of Peanut Breeding in China. Chinese Agricultural Science Bulletin, 30, 1-6.

http://www.wanfangdata.com.cn/details/detail.do?_type=perio\&id=zgnxtb20140900 $\underline{1}$

[60] Wang, C., Yang, Z., Chen, D., Zhang, J., Xu, J. and Yang, W. (2002) Production of Extra Large Podded and Small Podded Peanut Mutants Following Chemical Mutagen Treatment. Journal of Peanut Sciences, 31, 5-8.

[61] Wang, C., Wang, X., Tang, Y., Chen, D., Cui, F. and Yu, S. (2010) High Yielding Mutants Achieved by Injecting EMS into Peanut Flower Organs. Journal of Nuclear Agricultural Sciences, 24, 239-242. http://www.wanfangdata.com.cn/details/detail.do?_type=perio\&id=hnxb201002006

[62] Wang, C., Tang, Y., Wang, X., Wu, Q., Sun, Q., Gong, Q., Yang, Z., Song, G. and Wang, Z. (2016) Breeding of Huayu 9610, a High-Yielding Export-Type Conventional Large-Podded Peanut Cultivar, through Chemical Mutagenesis Combined with Intersectional Hybridization. Seed, No. 3, 100-101.

[63] Gao, A. (2016) The Traits and High-Yield Cultivation Technology for the New Processing Peanut Cultivar "Yuhanghua No. 1". Agricultural Science and Technology Communications, No. 6, 251-252.

[64] Li, M. (2004) Fundamental Studies on the Application of Plant Cell Engineering in Peanut (Arachis hypogaea L.) Breeding. Laiyang Agricultural College, Yantai.

[65] Chang, S., Sun, W., Xu, G., Wang, Z., Yin, M., Han, Q., Wei, Q., Li, J. and Shu, H. (2018) Isolating Method of Plant Protoplast and Its Research Advances of Application. Molecular Plant Breeding, 16, 1271-1277.

[66] Huang, B., Zhang, X., Miao, L., Qi, F., Shi, L., Dong, W. and Tang, F. (2015) Advances in Genetic Engineering of Peanut (Arachis hypogaea L.). Molecular Plant Breeding, 13, 228-234.

[67] Wang, X., Yu, S., Zhang, G., Wang, H., Feng, M., Dou, X., Fan, Q. and Yu, G. (2018) Optimization of Agrobacterium tumefaciens Mediated Peanut Transformation System and Study on Drought Tolerance of AIDREB2A Peanut. Journal of China Agricultural University, 23, 26-35.

[68] Bhatnagar-Mathur, P., Devi, M.J., Reddy, D.S., Lavanya, M., Vadez, V., Serraj, R., Yamaguchi-Shinozaki, K. and Sharma, K.K. (2007) Stress-Inducible Expression of AtDREB1 $A$ in Transgenic Peanut (Arachis hypogaea L.) Increases Transpiration Ef- 
ficiency under Water-Limiting Conditions. Plant Cell Reports, 26, 2071-2082. https://doi.org/10.1007/s00299-007-0406-8

[69] Vadez, V., Rao, S., Sharma, K.K., Bhatnagar-Mathur, P. and Devi, M.J. (2007) $D R E B 1 A$ Allows for More Water Uptake in Groundnut by a Large Modification in the Root/Shoot Ratio under Water Deficit. Journal of SAT Agricultural Research, 5, $1-5$. https://pdfs.semanticscholar.org/d268/6cfd8f8ab5e326cdaf616b6717c36509d320.pdf

[70] Devi, M.J., Bhatnagar-Mathur, P., Sharma, K.K., Serraj, R., Anwar, S.Y. and Vadez, V. (2011) Relationships between Transpiration Efficiency and Its Surrogate Traits in the rd29A:DREB1A Transgenic Lines of Groundnut. Journal of Agronomy and Crop Science, 197, 272-283. https://doi.org/10.1111/j.1439-037X.2011.00464.x

[71] Tan, M., Hu, B., Liu, C., Li, L. and Luo, H. (2010) Transformation AhNCED1 in Peanut (Arachis hypogaea L.). Journal of Tropical and Subtropical Botany, 18, 277-282.

[72] Asif, M.A., Zafar, Y., Iqbal, J., Iqbal, M.M., Rashid, U., Ali, G.M., Arif, A. and Nazir, F. (2011) Enhanced Expression of AtHX1 in Transgenic Ground Nut (Arachis hypogaea L.) Improves Salt and Drought Tolerance. Molecular Biotechnology, 49, 250-256. https://doi.org/10.1007/s12033-011-9399-1

[73] Qin, H., Gu, Q., Zhang, J., Sun, L., Kuppu, S., Zhang, Y., Burow, M., Payton, P., Blumwald, E. and Zhang, H. (2011) Regulated Expression of an Isopentenyltransferase Gene (IPT) in Peanut Significantly Improves Drought Tolerance and Increases Yield under Field Conditions. Plant and Cell Physiology, 52, 1904-1914. https://doi.org/10.1093/pcp/pcr125

[74] Qin, H., Gu, Q., Kuppu, S., Paez-Valencia, J., Mendoza, M., Hou, P., Chen, J., Qiu, X., Zhu, L., Zhang, X., Auld, D., Blumwald, E., Zhang, H., Gaxiola, R. and Payton, P. (2013) Expression of the Arabidopsis Vacuolar H+-pyrophosphatase Gene AVP1 in Peanut to Improve Drought and Salt Tolerance. Plant Biotechnology Reports, 7, 345-355. https://doi.org/10.1007/s11816-012-0269-5

[75] Langner, T., Kamoun, S. and Belhaj, K. (2018) CRISPR Crops: Plant Genome Editing toward Disease Resistance. Annual Review of Phytopathology, 56, 479-512. https://doi.org/10.1146/annurev-phyto-080417-050158

[76] Chen, K., Wang, Y., Zhang, R., Zhang, H. and Gao, C. (2019) CRISPR/Cas Genome Editing and Precision Plant Breeding in Agriculture. Annual Review of Plant Biology, 70, 667-697. https://doi.org/10.1146/annurev-arplant-050718-100049 